\title{
eixport: An R package to export emissions to atmospheric models
}

\section{Sergio Ibarra-Espinosa ${ }^{1}$, Daniel Schuch ${ }^{1}$, and Edmilson Dias de Freitas $^{1}$}

DOI: $10.21105 /$ joss.00607

\section{Software}

- Review ¿

- Repository ¿

- Archive [ᄌ

Submitted: 28 February 2018 Published: 25 April 2018

\section{Licence}

Authors of papers retain copyright and release the work under a Creative Commons Attribution $4.0 \mathrm{ln}$ ternational License (CC-BY).
1 Departamento de Ciências Atmosféricas, Universidade de São Paulo, Brasil

\section{Summary}

Emissions are the pollutant mass released into the atmosphere (Pulles and Heslinga 2010). The origin of the emissions can be human-made or anthropogenic or biogenic. The consequences of this pollution are complex affecting the atmosphere, human health, ecosystems, and infrastructure (Seinfeld and Pandis 2016). In fact, pollution caused 9 million premature deaths in 2015, $16 \%$ of all deaths worldwide (Landrigan et al. 2017).

An important tool for policy decision is air quality models. They have been used not only to study the impact of different emissions scenarios for policy making but also to understand the dynamics of air pollutants in various parts of the world (M. de F. Andrade et al. 2015). The inputs for an air quality models are meteorology and emissions. Currently, there are tools for developing emissions inventories such as the VEIN (S. Ibarra-Espinosa et al. 2017) and the EmissV models (Schuch 2017). However, the existing tools for inputting the emissions into the air quality models are not written in a user-friendly way, such as PREP-Chem written in Fortran and C (S. Freitas et al. 2011). Also, as the R language has a growing community, including statistical $\mathrm{R}$ packages for model evaluation and validation, such as openair [], air quality modelers already familiar with $\mathrm{R}$ would tend to use 'eixport' for inputing data into the appropiate format for each model without the need of deep knowledge in a specific model language. Therefore, we developed eixport, a tool for inputting data into atmospheric models using $\mathrm{R}$ (R Core Team 2017).

eixport imports functions form the $\mathrm{R}$ packages sf (E. Pebesma 2017) which provides functions for spatial vector data, providing bindings to the GDAL, GEOS, and Proj.4 $\mathrm{C}++$ libraries. Also, eixport import functions from the package ncdf4 (Pierce 2017), which interface to Unidata netCDF Format Data Files, and from the raster package (Hijmans 2017), which provides functions to gridded data.

\section{Functions and data}

eixport count with the following functions:

\begin{tabular}{ll}
\hline Function & Description \\
\hline emisco & Dataset of Emissions from VEIN demo \\
emis_opt & List of WRF emission species \\
rawprofile & A matrix to temporally distribute emissions \\
wrf_create & Create WRF-Chem inputs based on a WRFinput file \\
wrf_get & Reads variables from WRF-Chem inputs \\
wrf_grid & Creates spatial feature (sf) polygon grid from WRFinput file \\
wrf_plot & Simple plot from wrf emission file \\
wrf_profile & returns a traffic intensity profile (based on wrf file Times)
\end{tabular}




\begin{tabular}{ll}
\hline Function & Description \\
\hline wrf_put & Function to write variables in WRF-Chem inputs \\
to_brams_spm & Produce inputs for BRAMS SPM (E. D. de Freitas et al. 2005) \\
to_rline & Produce inputs for R-Line (Snyder et al. 2013) \\
to__wrf & Distribution of emissions for WRF-Chem (G. A. Grell et al. 2005) \\
to_as4wrf & Produce data-frame to be used with NCL AS4WRF (Vara-Vela et al. 2016) \\
\hline
\end{tabular}

\section{Examples}

The following example creates a directory EMISS and then create a wrfchem input in that file. The package already counts with wrfinput files required to run eixport and create inputs for WRF-Chem. The line data(Lights) load a matrix of night light to spatially distribute the emissions. The perfil argument is used to temporally distribute the emissions. Lastly, the function to_wrf in one line reads the $1521983 t \cdot y^{-1}$ of CO, spatially distribute it using nighttime traffic matrix Lights, temporally distribute it with the perfil, injecting the array of emissions directly into the wrfchemi file. The colour palette is "mpl_inferno" from the R package cptcity (Sergio Ibarra-Espinosa 2017).

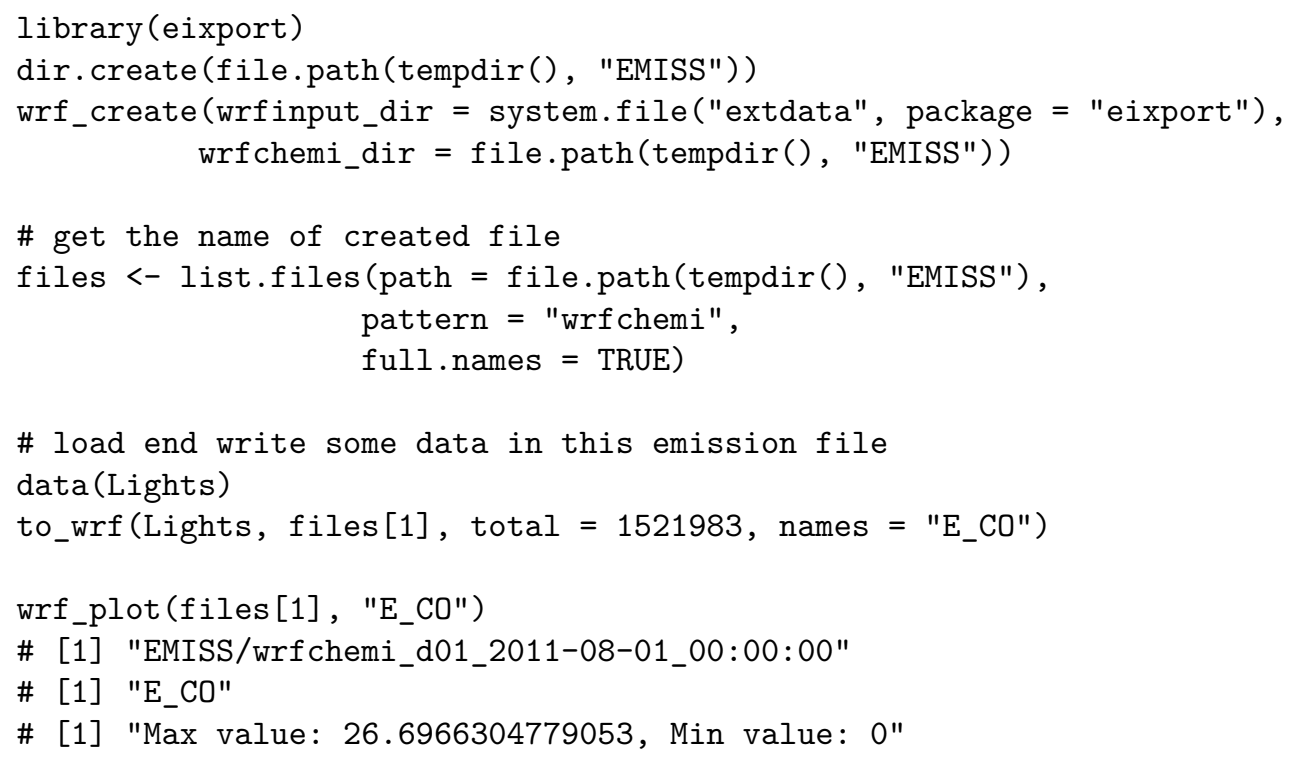

The resulting plot can be seen in the Fig. 1.

The $\mathrm{R}$ package eixport is available at the repository https://github.com/atmoschem/ eixport. To ensure the usability of the package, in any commit to GitHub, eixport is installed in Ubuntu via Travis-CI (https://travis-ci.org/atmoschem/eixport) and Windows via Appveyor (https://ci.appveyor.com/project/Schuch666/eixport). Also, eixport is already on CRAN https://CRAN.R-project.org/package=eixport. Moreover, this packages tests functions with the suite CodeCov (https://codecov.io/) and the r package covr (Hester 2017), achieving $89 \%$ of coverage (https://codecov.io/github/atmoschem/eixport). 


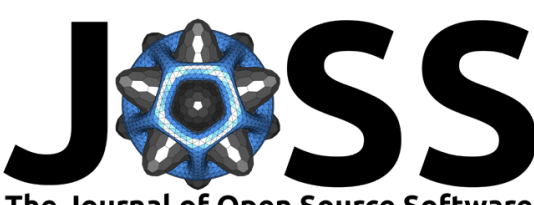

The Journal of Open Source Software

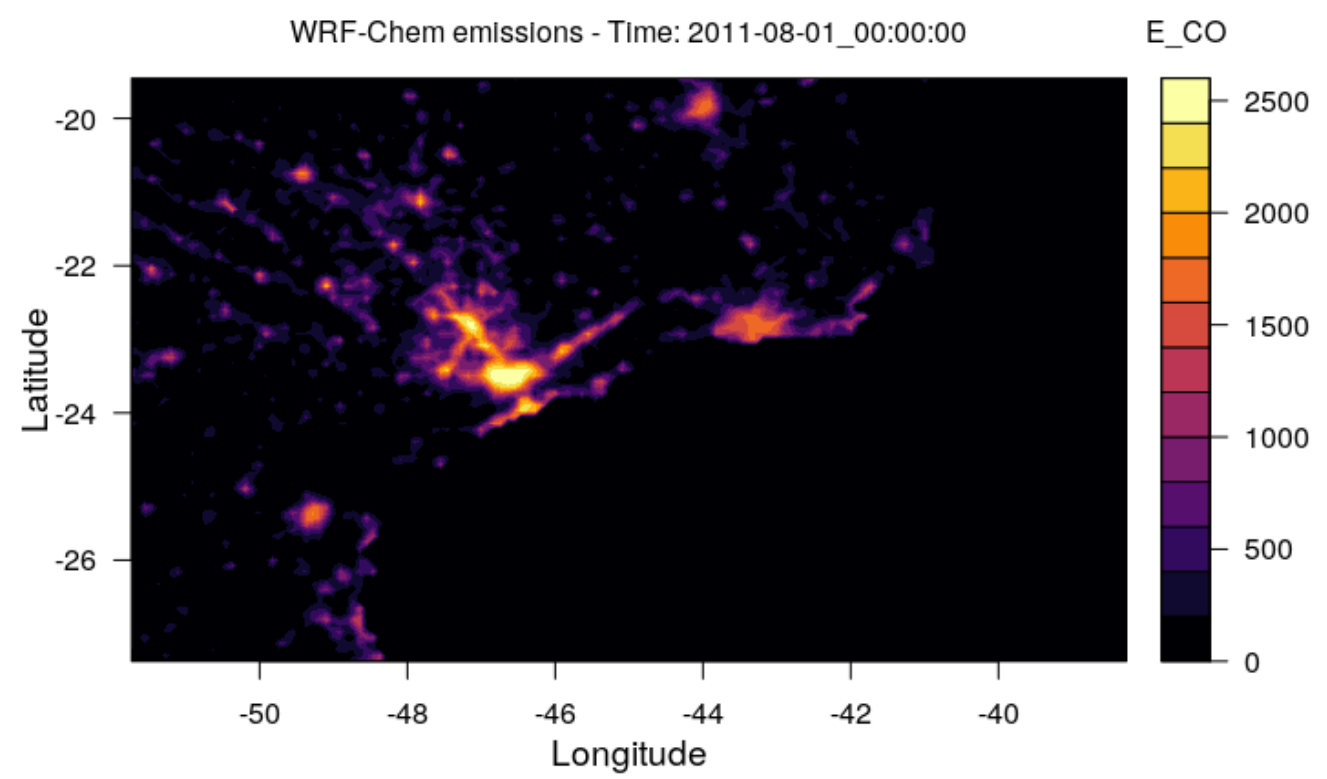

Figure 1: WRF-Chem emisisons of $\mathrm{CO}(\mathrm{t} / \mathrm{y})$

\section{Acknowledgements}

The development of eixport was supported by postdoc grans fro the Fundação de Universidade de São Paulo and Fundação Coordenação de Aperfeiçoamento de Pessoal de Nível Superior.

\section{References}

Andrade, Maria de Fatima, Rita Y Ynoue, Edmilson Dias Freitas, Enzo Todesco, Angel Vara Vela, Sergio Ibarra, Leila Droprinchinski Martins, Jorge Alberto Martins, and Vanessa Silveira Barreto Carvalho. 2015. "Air Quality Forecasting System for Southeastern Brazil." Frontiers in Environmental Science 3. Frontiers:1-12. https://doi.org/10. 3389 /fenvs.2015.00009.

Freitas, Edmilson Dias de, Leila Droprinchinski Martins, Pedro Leite da Silva Dias, and Maria de Fátima Andrade. 2005. "A Simple Photochemical Module Implemented in Rams for Tropospheric Ozone Concentration Forecast in the Metropolitan Area of Sao Paulo, Brazil: Coupling and Validation." Atmospheric Environment 39:6352-61. https: //doi.org/10.1016/j.atmosenv.2005.07.017.

Freitas, SR, KM Longo, MF Alonso, M Pirre, V Marecal, G Grell, R Stockler, RF Mello, and M Sánchez Gácita. 2011. "PREP-Chem-Src-1.0: A Preprocessor of Trace Gas and Aerosol Emission Fields for Regional and Global Atmospheric Chemistry Models." Geoscientific Model Development 4 (2). Copernicus GmbH:419. https://doi.org/10.5194/ gmd-4-419-2011.

Grell, Georg A, Steven E Peckham, Rainer Schmitz, Stuart A McKeen, Gregory Frost, William C Skamarock, and Brian Eder. 2005. "Fully Coupled 'Online' Chemistry Within the Wrf Model." Atmospheric Environment 39 (37). Elsevier:6957-75. https://doi.org/ 10.1016/j.atmosenv.2005.04.027. 
Hester, Jim. 2017. Covr: Test Coverage for Packages. https://cran.r-project.org/ package $=$ covr.

Hijmans, Robert J. 2017. Raster: Geographic Data Analysis and Modeling. https://cran. r-project.org $/$ package $=$ raster.

Ibarra-Espinosa, S., R. Ynoue, S. O'Sullivan, E. Pebesma, M. D. F. Andrade, and M. Osses. 2017. "VEIN V0.2.2: An R Package for Bottom-up Vehicular Emissions Inventories." Geoscientific Model Development Discussions 1:1-29. https://doi.org/10.5194/ gmd-2017-193.

Ibarra-Espinosa, Sergio. 2017. Cptcity: 'Cpt-City' Colour Gradients. https://cran. r-project.org/package= vein.

Landrigan, Philip J, Richard Fuller, Nereus JR Acosta, Olusoji Adeyi, Robert Arnold, Abdoulaye Bibi Baldé, Roberto Bertollini, et al. 2017. "The Lancet Commission on Pollution and Health." The Lancet. Elsevier. https://doi.org/10.1016/S0140-6736(17) 32345-0.

Pebesma, Edzer. 2017. Sf: Simple Features for R. https://github.com/r-spatial/sf/.

Pierce, David. 2017. Ncdf4: Interface to Unidata netCDF (Version 4 or Earlier) Format Data Files. https://cran.r-project.org/package=ncdf4.

Pulles, Tim, and Dick Heslinga. 2010. "The Art of Emission Inventorying." TNO, Utrecht. https://doi.org/10.13140/RG.2.1.2082.8007.

R Core Team. 2017. R: A Language and Environment for Statistical Computing. Vienna, Austria: R Foundation for Statistical Computing. https://www.r-project.org/.

Schuch, Daniel. 2017. Emiss V: Top-down Methods to Create Vehicular Emissions. https: //github.com/atmoschem/EmissV.

Seinfeld, John H, and Spyros N Pandis. 2016. Atmospheric Chemistry and Physics: From Air Pollution to Climate Change. John Wiley \& Sons. https://doi.org/10.1063/1.882420.

Snyder, Michelle G, Akula Venkatram, David K Heist, Steven G Perry, William B Petersen, and Vlad Isakov. 2013. "RLINE: A Line Source Dispersion Model for NearSurface Releases." Atmospheric Environment 77. Elsevier:748-56. https://doi.org/10. 1016/j.atmosenv.2013.05.074.

Vara-Vela, A, Maria F Andrade, Prashant Kumar, Rita Y Ynoue, and AG Muñoz. 2016. "Impact of Vehicular Emissions on the Formation of Fine Particles in the Sao Paulo Metropolitan Area: A Numerical Study with the Wrf-Chem Model." Atmospheric Chemistry and Physics 16 (2). Copernicus GmbH:777-97. https://doi.org/10.5194/acp-16-777-2016. 